\title{
High-Temperature Electronics: Status and Future Prospects in the 21st Century
}

\author{
F. Touati*, F. Mnif and A. Lawati \\ Department of Electrical and Computer Engineering, Sultan Qaboos University, P. O. Box 33, Al-Khoud, Muscat, 123, \\ Sultanate of Oman
}

Received 2 June 2004; accepted 18 September 2005

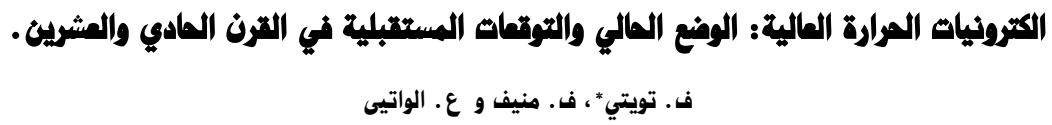

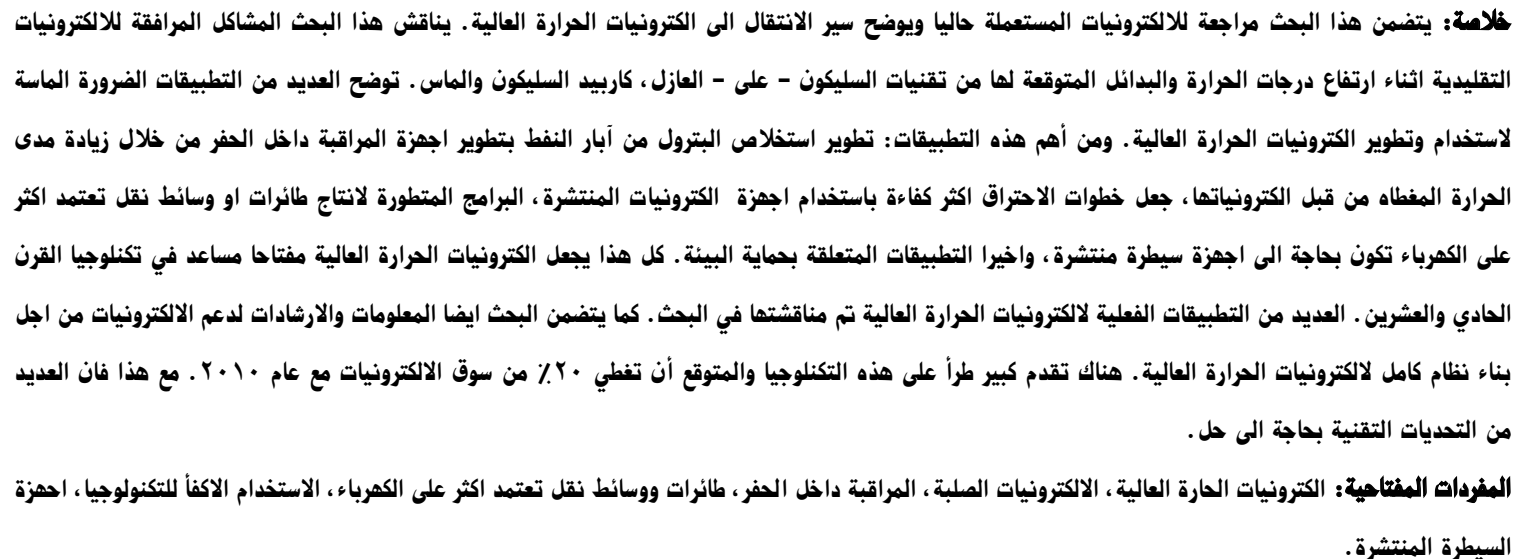

\begin{abstract}
This paper reviews the state of current electronics and states the drive toward high-temperature electronics. The problems specific to high-temperature effects on conventional electronics and prospects of alternative technologies like silicon-on-insulator, silicon carbide, and diamond are discussed. Improving petroleum recovery from oil wells with hightemperature coverage of downhole electronics, making combustion processes more efficient utilizing embedded electronics, programs for More Electric Aircraft and Vehicles necessitating distributed control systems, and environmental protection issues stress the need to use and develop high-temperature electronics. This makes high-temperature electronics a key-enabling technology in the 21st century. Actual applications using high-temperature electronics are discussed in some details. Also information and guidelines are included about supporting electronics needed to make a complete high-temperature system. The technology has been making major advancements and is expected to account for $20 \%$ of the electronics market by 2010. However, many technical challenges have to be solved.
\end{abstract}

Keywords: High temperature, Hard electronics, Downhole monitoring, Electric aircrafts and vehicles, Efficient use of energy, Distributed control systems

\section{Introduction}

The advanced society is strongly supported by electronics. With the progress of society, much more aid of electronics in the wide area including hard environment ("Hard Electronics"), such as high-temperature, high power, high irradiation, and high frequency, is needed. The term of "Hard Electronics" was incepted in Japan in 1991. It means a new kind of electronics needed in hard circumstances utilizing hard materials, which are essentially tough themselves and very hard to be handled. The hard materials involve wide band gap semiconductors and new kind of oxides (Ma et al. 2002; Prelas et al. 2002;

*Corresponding author's e-mail: touatif@squ.edu.om
Spitsyn et al. 2002). Hard electronics research continued to develop throughout the 80s with increasing emphasis on high-temperature operation, i.e. high-temperature electronics (HTEs) (Patrick et al. 1997). The energy crisis precipitated by the Middle East saw a clear focus on improving petroleum recovery from oil wells by improved down hole monitoring, necessitating increased temperature coverage by the electronic systems. There are many equally potential applications with increasing commercial opportunities afforded by programs of More Electric Aircraft and More Electric Vehicles (Kodjak, 1993 and 1996).

A main theme also has been in distributed control systems for improved reliability and increased fuel economy, either directly by improved combustion control or indi- 
rectly by reduced weight by reducing the requirement for ancillary equipment. There are still many problems to overcome for the full adoption of HTE systems in "everyday" electronics. High-temperature designs need components rated to operate in the hard environment in which they will be used.

This paper reviews the state and future prospects of HTEs as a technology increasingly affecting strategic sectors in the 21st century. Some details of actual applications using HTEs have been discussed. Information has also been included about components and materials needed to make a complete high-temperature system.

\section{High-Temperature Effects on Device Properties}

\subsection{General Tendency}

As temperature increases in a semiconductor, there are challenging issues to resolve (Lall et al. 1997):

- Intrinsic carrier density increases.

- Junction leakage current increases exponentially (p-n junctions, BJTs, and FETs), which presents the biggest problem.

- Device parameters vary (forward bias voltage, threshold voltage, forward current, carrier mobility, input impedance, transconductance, susceptibility to latchup).

- Electromigration of interconnection traces increases.

- Chemical reactivity of ohmic contacts increases.

- Dielectric breakdown strengths decrease.

- TEC mismatches stress the die mechanically.

The most important physical properties for a good high- temperature semiconductor material are a wide bandgap and high thermal conductivity.

- Bandgap, because it determines the amount of leakage current across the junction.

- Thermal conductivity, because it determines the semiconductor's ability to dissipate heat to the ambient environment.

The above effects show that the temperature is a major limitation for electronic devices. The upper temperature limit for conventional electronics is $100^{\circ} \mathrm{C}$, with some special military components being operated at a maximum of $125^{\circ} \mathrm{C}$ as shown in Fig. 1. Possible way to cope with a high-temperature environment is to use active cooling systems and to place electronics some distance away in a moderate environment. However, large, heavy, and complex cooling systems and the cabling and interconnections they require are not at all advantageous from the viewpoint of accuracy, reliability, size and cost. The development of HTEs is, therefore, eagerly sought after.

\subsection{Bipolar Technology}

Typically, amplifiers must have low offset, high impedance, and high gain to minimize errors in a control loop. Unfortunately, bipolar junction transistors, which are typically used for these reasons, do not work well at high temperatures because of:

- Forward current gain increases with temperature at about $30 \% / 100^{\circ} \mathrm{C}$.

- Forward voltage decreases at about $200 \mathrm{mV} / 100^{\circ} \mathrm{C}$.

- Reverse leakage of the base/collector junction with open emitter doubles every $8^{\circ} \mathrm{C}$.

\section{${ }^{\circ} \mathrm{C}$}

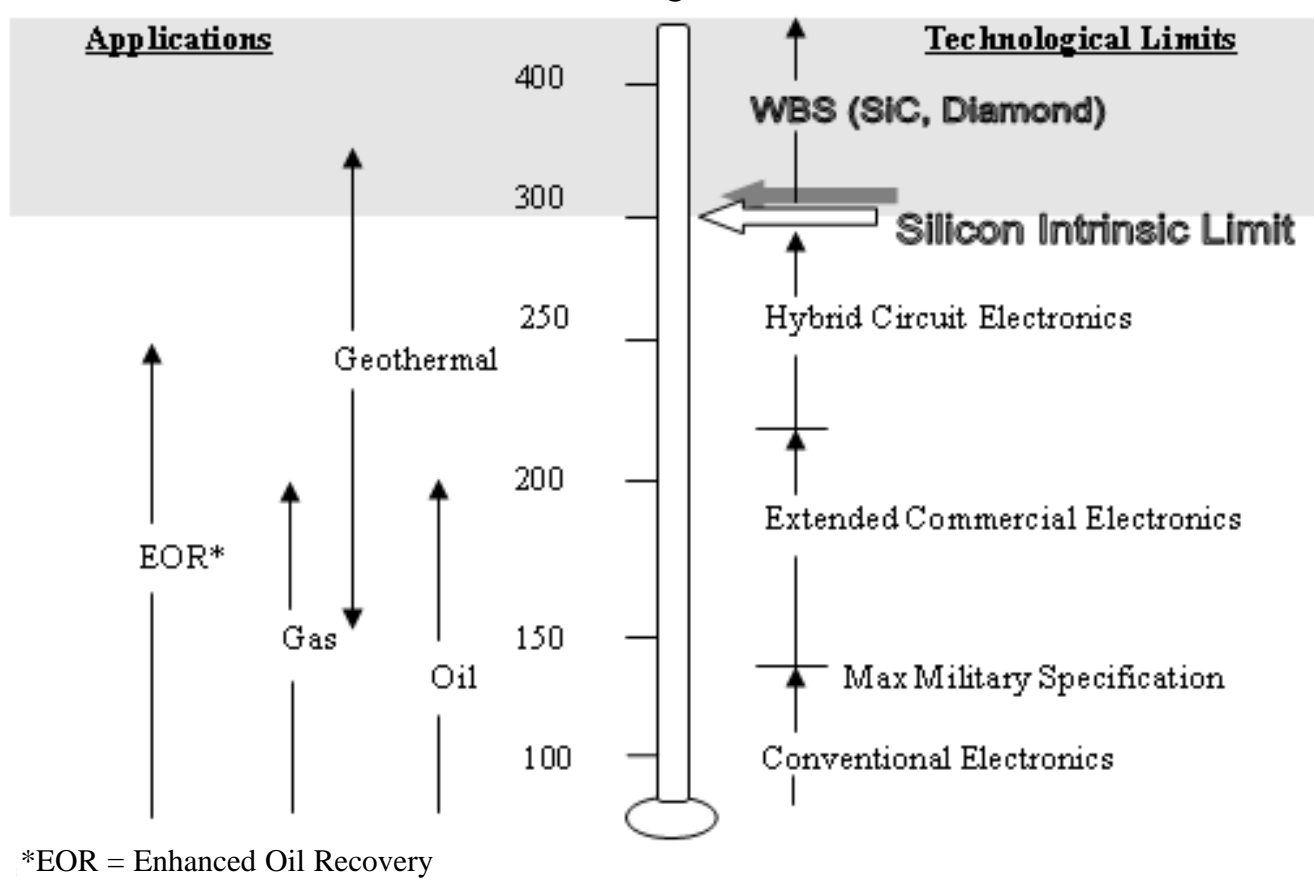

Figure 1. Temperature limits for electronic applications 
- Resistivity of silicon (Si), which is temperature dependent.

- A loss of linearity that occurs in the saturation region with temperature increase.

Increasing leakage current, which is often the dominant effect, eventually causes loss of rectification and isolation. Bipolar circuits start to fail above $150^{\circ} \mathrm{C}$. In the bipolar transistor characteristics, not only is the collector current dramatically reduced, but there is significant distortion and loss of linearity at high temperatures. Also, the output resistance is not constant.

\subsection{CMOS Technology}

At high temperatures, CMOS devices also experience reduced performance. Unfortunately, most devices are not tested above $150^{\circ} \mathrm{C}$.

Characterization testing of a typical MOSFET device in the range of $100^{\circ} \mathrm{C}-200^{\circ} \mathrm{C}$ indicates that:

- Breakdown voltage increases with temperature at about $8 \% / 100^{\circ} \mathrm{C}$.

- On-resistance increases with temperature at about $70 \% / 100^{\circ} \mathrm{C}$.

- Leakage current increases rapidly with temperature, changing four orders of magnitude $/ 100^{\circ} \mathrm{C}$, doubling every $8{ }^{\circ} \mathrm{C}$.

- Gate-source threshold voltage decreases with temperature, about $24 \% / 100^{\circ} \mathrm{C}$.

- Conventional CMOS and MOSFET devices usually operate to $160^{\circ} \mathrm{C}$. With dielectric isolation, this limit can be extended to about $200^{\circ} \mathrm{C}$, and when designed for high temperature, to about $300^{\circ} \mathrm{C}$.

\section{Why Are High-Temperature Electronics Needed?}

The industries most interested in designing products using HTEs today can be broken along field lines as follows:

\subsection{Oil and Gas Well Logging}

The energy crises of the 70s backed by a second energy crisis precipitated by the Middle East nations emphasis on the need for a clear focus on improving petroleum recovery from oil wells by improved downhole monitoring, necessitated increased temperature coverage by downhole instruments. This requires sensors and data acquisition systems used to $\log$ the environment around drilling heads in wells, measuring reservoir potential and environmental conditions, and geothermal implementation of 'permanent sensors' intended to allow long life; up to 5 years operation with no failures. This will also help discovering new markets in deeper (i.e. hotter) wells operating at $400^{\circ} \mathrm{C}$ and above.

This has presented electronics with a challenging environment. Locating an instrument for pressure or flow measurement at the end of 3 miles of wire poses problems for electronics including temperatures of $185^{\circ} \mathrm{C}$ (extended periods) to $250^{\circ} \mathrm{C}$ (shorter periods). Geothermal wells push continuous operating temperatures to $300^{\circ} \mathrm{C}$, with survival to $350^{\circ} \mathrm{C}$ required (Normann, 1998). Traditional limits of several hours to 100 hours are being pushed out to several thousand hours, and in the case of permanent gages, to several years of continuous operation. There are three typical types of instruments which are discussed below.

\subsubsection{Logging Tools}

Logging tools are deployed for gathering snapshot information revealing the quality and potential production of the well. These can be wire-connected (wireline tools, receiving power and communications from the surface) or steel cable connected (memory tools, which are self-powered and contain memory which is retrieved with the tool).

\subsubsection{Measurement while Drilling Tools}

These are used for directional drilling information such as hole inclination, hole azimuth, and the tool face direction. In addition, other measurements are now performed including resistivity, natural gamma, and neutral density. Downhole weight on bit, torque, vibration levels and accelerations are sometimes also incorporated into the measurement. This environment is extremely rugged requiring endurance of high vibrations and shock and thermal cycling every several days as the bit is pulled up and changed. Because of the high cost of drilling operations ( $\$ 20,000$ to $\$ 100,000$ per day) these instruments need to be highly reliable. In some cases, the drilling operation is allowed to continue without operating instrumentation.

\subsubsection{Permanent Gauges}

Permanent gauges are installed in producing wells and monitored at the surface periodically over several years. Temperature, pressure, flow and different chemical sensors are deployed. These devices must have good longterm stability without susceptibility to premature wearout mechanisms such as electromigration (discussed later).

\subsection{Military and Space}

The mechanisms of failure of electronic components are being looked at afresh. Until quite recently the US Military Handbook 217 provided design guidelines linking failure rate exponentially to steady state temperature which led to overly large cooling systems adding weight, cost and complexity to aircraft. From the engine manufacturers' viewpoint, transducers with high-temperature capability would enable more accurate assessment of parameters in hard environments. This would facilitate the extended use of data buses to replace dedicated wiring from engine probes to remote electronic processing circuits. The impact would give considerable weight and reliability. Total weight of connectors and wiring in the harness is around $60-65 \mathrm{~kg}$ in current large civil aircraft.

In the aerospace industry, HTEs could potentially 
enable improved system designs resulting in lighter, faster, cheaper, and more fuel-efficient aircraft. Most severe environment is around the engine. Controlling electronics operate in an ambient of up to $250^{\circ} \mathrm{C}$ and cooled by routing and interfacing engine fuel (at less than $105^{\circ} \mathrm{C}$ ) with the heat sinks. In two specialist applications, electronics already operate above $100^{\circ} \mathrm{C}$ :

- In electronic braking systems for large aircraft,

- UV flame detection for turbine engine combustor con trol.

HTEs are also required for the implementation of multiplexed systems for gas turbine engine control, which would enable complex cooling and connection requirements to be eliminated. Studies done at the US Air Force Research Laboratory show that better regulation of engine thrust can result in doubling of the thrust/weight ratio, $40 \%$ fuel burn reduction, at the same time providing a $35 \%$ decrease in engine life cycle costs (Lewis, 1998). To achieve these goals, control logic must be designed to use a broad array of hundreds of sensors/actuators operating over a wide operating temperature range to control thrust while protecting against aerodynamic, thermal, or material strength limitations. The engine case is a significant source of radiant heat, approaching $560^{\circ} \mathrm{C}$ at high altitudes. Conventional uncooled electronics cannot be used here because of thermally induced wear factors leading to degradation and premature failure. Although fuel cooling has been very effective at improving the electronics environment, this approach favors centralized control architectures as well as the added weight and space required for the cooling pumps, heat exchanger, and piping.

Also, deep space exploration of planets like Neptune requires electronics which are able to operate below $-220^{\circ} \mathrm{C}$ on the surface of Triton or Pluto. Electronics for Venus 2006-2007 missions need to operate at above $470^{\circ} \mathrm{C}$ and it seems that suitable HTEs may not be ready in time except for "grab-and-go" or limited life" operations.

\subsection{Automotive}

There is a rising need for More Electric Aircraft and More Electric Vehicles which are more reliable, faster, simpler, lighter, and less polluting. The automotive sector presents, by far, the largest potential market for HTEs. However, automotive applications will prove to be the most difficult for HTE to penetrate, due to:

- Extremely pricing pressures,

- Very demanding requirements for long term reliability,

- The long cycles for new designs.

Five automotive applications will provide the main drivers for HTEs and high-temperature power devices:

- Engine control,

- Transmission control,
- ABS (antilock braking systems),

- Active suspensions,

- Sensors for wheel speed and MAP (Manifold Absolute Pressure (systems).

HTEs and sensors are becoming increasingly necessary for automotive control applications such as Engine Control Units (ECUs), in-cylinder pressure sensing and camshaft position sensing because of international requirements to rapidly reduce engine emissions. Reducing emissions depends on more precise and local control of valve timing, which in turn depends on primary, not inferential, sensing of cylinder pressure and camshaft position. Improveing the precision of these measurements requires the sensors and signal conditioning electronics to be mounted close to, or in some cases inside, the engine itself. ECUs, typically mounted on the firewall of the engine compartment, can also contribute to reduce emissions by being mounted on the engine itself. The shorter control loops to/from the ECU lead to more precise control.

\subsection{Efficient Energy Use and Environment Protection}

The global energy demand is growing at a rate of 3 to $4 \%$ a year. Accordingly, the world energy consumption will double around 2050. A survey of future carbon dioxide emission predicts environmental crisis such as:

- Increase in atmospheric temperature,

- Rise of sea surface level,

- So this will be a challenge for mankind to avoid the crisis in the 21st century. Three basic technological measures to take are as follows,

- Energy system change from fossil fuel to non-fossil fuel use,

- High efficiency energy utilization,

- Control of carbon dioxide emission and collection.

As to the energy system change, some report says that today's ratio of fossil ( $80 \%$ of the 11 terawatts) to non-fossil energy (20\%) utilization have to be changed into the ratio of $40 \%$ to $60 \%$ of the 30 terawatt total until middle of the 21st century to stabilize carbon dioxide concentration in the air (Matin, 1998). Most of non-fossil energy will be electricity, supplied by atomic energy and reproducible natural energy such as solar energy, water power, wind power and terrestrial heat. In Japan, about $40 \%$ of the total input energy has been already supplied by electricity. The term high-efficiency energy utilization is two fold. First, it will be more and more important for mankind to develop high-efficiency electrical energy utilization social system in this century, because electrical energy demand will rapidly grow in the world. Second, improvement of combustion control system is necessary to attain efficient energy use and minimal pollution. As to 


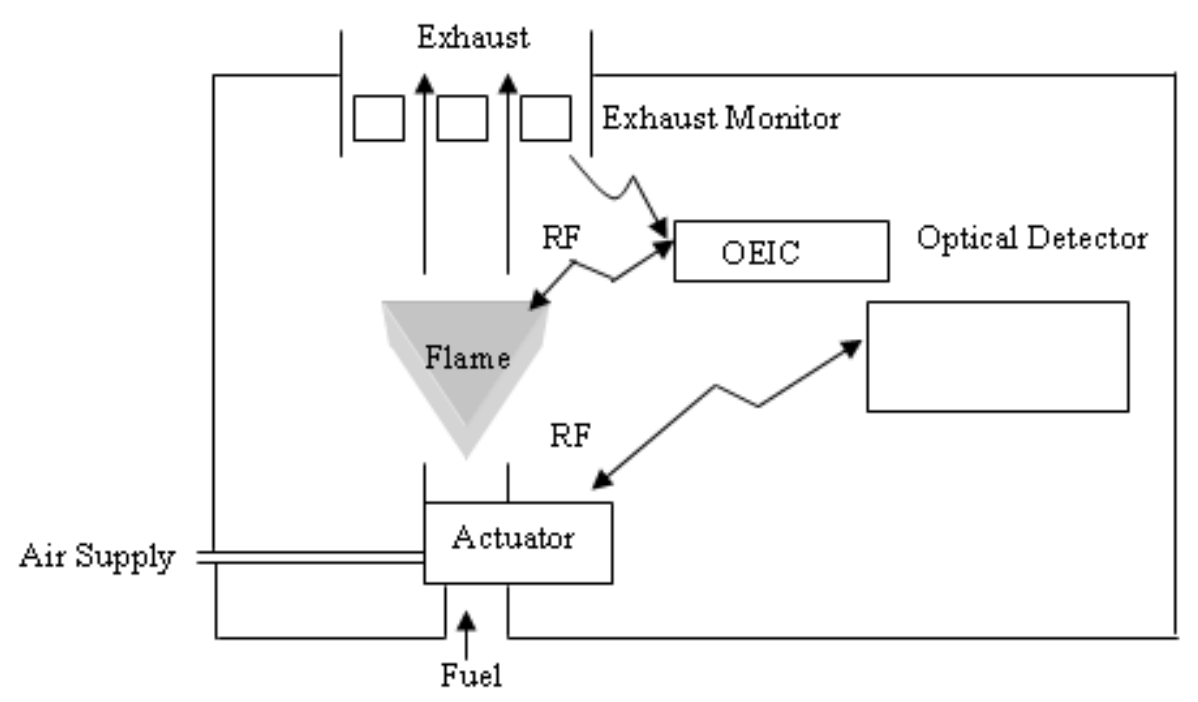

Figure 2. Schematic new combustion control system using SiC-based control devices

the first, expected electric power leading energy technologies for this century are:

- Power generation: atomic, new systems to find out

- Power transmission: power system linkage

- Power storage: pumped storage, hydraulic generation

- Power conversion: EV, high speed railway system (inverters)

where power electronics will be essential for the new technologies. The corresponding power devices must, therefore, be of:

- Low power consumption,

- Higher switching speed,

- Higher temperature operation.

As to the second, in Japan, in 1994 the Ministry of International Trade and Industry (MITI) began the project called "Research and Development on Combustion Control for Energy conservation". The project had a term of 6 years. MITI has delegated management of the research and development to the Ion Engineering Research Institute Corporation through the New Energy and Industrial Technology Development Organization (NEDO). The objectives of this R\&D are to establish technologies for realizing SiC-based devices applicable to the advanced combustion control system as shown in Fig. 2 . More specifically, to achieve the advanced new system, $\mathrm{R} \& \mathrm{D}$ is focused on $\mathrm{SiC}$ devices operable in a high-temperature and oxidizing environment.

\subsection{Communication Sector}

The communication sector is also very much concerned by hard electronics devices. The communication systems in 1970's to 1980's were characterized by:

- High-power land/satellite base stations and home receivers for broadcasting,

- Analog transceiver for wireless telecommunications and cable network communication.

From the beginning of 1990 's, new systems characterized by:

- Very small-sized personal mobile telephones (cellular),

- Personal computer network (Internet).

have been implemented. Keywords in these new systems: digital, high speed, mobile and personal. In the beginning of this century, $50 \mathrm{cc}$ size and $50 \mathrm{~g}$ weight cellular handset (can be wristband type) with a high RF performance has appeared. Also, for this century various high-frequency communications are projected. Very small base stations are strongly demanded in order to install them on rooftops of buildings. Hard electronics will contribute a great deal:

\begin{tabular}{|c|c|c|}
\hline Requirement & & Effect on Product \\
\hline $\begin{array}{l}\text { Explore new, } \\
\text { deeper oil wells }\end{array}$ & $\rightarrow$ & $\begin{array}{l}\text { Hotter, i.e., } \\
\text { equipment exposed to } \\
\text { higher temperatures }\end{array}$ \\
\hline $\begin{array}{l}\text { Downhole } \\
\text { drilling cost } \\
\text { increased }\end{array}$ & $\rightarrow$ & $\begin{array}{l}\text { Durable and more } \\
\text { reliable equipment } \\
\text { required }\end{array}$ \\
\hline $\begin{array}{l}\text { Improve aircraft } \\
\text { performance }\end{array}$ & $\rightarrow$ & $\begin{array}{l}\text { Distributed engine } \\
\text { controls }\end{array}$ \\
\hline $\begin{array}{l}\text { Optimize fuel } \\
\text { consumption }\end{array}$ & $\rightarrow$ & $\begin{array}{l}\text { Lighter controls and } \\
\text { monitors }\end{array}$ \\
\hline $\begin{array}{l}\text { Remove cooling } \\
\text { systems }\end{array}$ & $\rightarrow$ & $\begin{array}{l}\text { Hotter operating } \\
\text { conditions with no } \\
\text { airflow or heat sink }\end{array}$ \\
\hline
\end{tabular}

\subsection{Other Applications}

In addition, markets needing HTEs are forming in the areas of integrated motor controls, industrial process controls, building fire safety controls, environmental test equipment, and other areas. A number of recent requirement changes have pushed the upper operating temperature range limit higher, as shown in Table 1. 
Table 1. International technology roadmap for semiconductors ambient operating temperatures for hard environments (automotive)

\begin{tabular}{|c|c|c|c|c|c|c|c|}
\hline & 2001 & 2002 & 2003 & 2004 & 2005 & 2006 & 2007 \\
\hline Complex ICs & $\begin{array}{l}-40^{\circ} \mathrm{C} \text { to } \\
+125^{\circ} \mathrm{C}\end{array}$ & $\begin{array}{l}-40^{\circ} \mathrm{C} \text { to } \\
+125^{\circ} \mathrm{C}\end{array}$ & $\begin{array}{l}-40^{\circ} \mathrm{C} \text { to } \\
+125^{\circ} \mathrm{C}\end{array}$ & $\begin{array}{l}-40^{\circ} \mathrm{C} \text { to } \\
+125^{\circ} \mathrm{C}\end{array}$ & $\begin{array}{l}-40^{\circ} \mathrm{C} \text { to } \\
+125^{\circ} \mathrm{C}\end{array}$ & $\begin{array}{l}-40^{\circ} \mathrm{C} \text { to } \\
+125^{\circ} \mathrm{C}\end{array}$ & $\begin{array}{l}-40^{\circ} \mathrm{C} \text { to } \\
+125^{\circ} \mathrm{C}\end{array}$ \\
\hline Power/Linear & $\begin{array}{l}-40^{\circ} \mathrm{C} \text { to } \\
+150^{\circ} \mathrm{C}\end{array}$ & $\begin{array}{l}-40^{\circ} \mathrm{C} \text { to } \\
+150^{\circ} \mathrm{C}\end{array}$ & $\begin{array}{l}-40^{\circ} \mathrm{C} \text { to } \\
+180^{\circ} \mathrm{C}\end{array}$ & $\begin{array}{l}-40^{\circ} \mathrm{C} \text { to } \\
+180^{\circ} \mathrm{C}\end{array}$ & $\begin{array}{l}-40^{\circ} \mathrm{C} \text { to } \\
+200^{\circ} \mathrm{C}\end{array}$ & $\begin{array}{l}-40^{\circ} \mathrm{C} \text { to } \\
+200^{\circ} \mathrm{C}\end{array}$ & $\begin{array}{l}-40^{\circ} \mathrm{C} \text { to } \\
+200^{\circ} \mathrm{C}\end{array}$ \\
\hline
\end{tabular}

Standard, commercial off the shelf (COTS) bulk Si processed semiconductors, however, are not able to handle these increased demands. They are designed for a service range of $-55^{\circ} \mathrm{C}$ to $+70^{\circ} \mathrm{C}$ for commercial, $+85^{\circ} \mathrm{C}$ for industrial or $+125^{\circ} \mathrm{C}$ for military temperature range. Use of these components beyond their intended range is not specified or recommended by their manufacturers.

The discussion above on the various strategic sectors emphasizes the need for devices having higher temperature ratings. In fact, the 2002 five-year update to the International Technology Roadmap for Semiconductors (ITRS) did not reflect the immediate need for higher operating temperatures for complex integrated circuits or ASICs; but did recognize increasing temperature requirements for power and linear devices as shown in Table 1 (Johnson, 2004).

Table 2. The main physical parameters for various semiconductors

\begin{tabular}{|c|c|c|c|}
\hline Element & $\begin{array}{c}\text { Bandgap } E_{g} \\
(\mathrm{eV})\end{array}$ & $\begin{array}{c}\text { Electron } \\
\text { mobility } \\
(\mathrm{cm} / \mathrm{s})\end{array}$ & $\begin{array}{c}\text { Breakdown } \\
\text { voltage } \\
(\mathrm{V} / \mathrm{cm})\end{array}$ \\
\hline Si & 1.12 & $1 \times 10^{7}$ & $2 \times 10^{4}$ \\
\hline $\mathrm{Ge}$ & 0.67 & $5 \times 10^{7}$ & $7 \times 10^{3}$ \\
\hline GaAs & 1.43 & $2 \times 10^{7}$ & $3 \times 10^{4}$ \\
\hline $\mathrm{SiC}$ & $2.2-3.00$ & $2 \times 10^{7}$ & $25 \times 10^{5}$ \\
\hline Diamond & 4.8 & $1 \times 10^{7}$ & $8 \times 10^{5}$ \\
\hline
\end{tabular}

Nevertheless, in the 2003 edition of the ITRS, the maximum junction temperatures identified for hard-environment complex integrated circuits was raised to $150^{\circ} \mathrm{C}$ through 2018 (Johnson, 2004). The ambient operating temperature extreme for hard-environment complex integrated circuits was defined as $40^{\circ} \mathrm{C}$ to $125^{\circ} \mathrm{C}$ through 2009, increasing to $40^{\circ} \mathrm{C}$ to $150^{\circ} \mathrm{C}$ for 2010 and beyond.

\section{Status and Prospects of High-Temperature Electronics}

\subsection{High-Temperature Semiconductor Techno- logies}

Generally, the main part of electronics is composed of semiconductors. Ordinary semiconductors $\mathrm{Si}$, germanium (Ge), and gallium arsenide (GaAs), have rather small energy gaps as shown in Table 2.

Due to the limitation of material properties caused by the bandgap, they cannot withstand severe environment. So, we need wide bandgap semiconductors such as silicon carbide (SiC), gallium nitride, diamond, and oxides. The same reason has been behind the interest shown on Si over Ge (ESi, gap > EGe, gap) fifty years ago and the technological development of the Si industry so far. However, as Table 3 shows, Si and silicon on insulator (SOI) are the only technologies with good high-temperature characteristics that is mature enough for production use.

SOI technology was originally developed to meet Aerospace needs for instrumentation, data acquisition and distributed control. The temperature and reliability requirements for the Aerospace applications supported the

Table 3. High-temperature tolerant semiconductor technologies (HITEN, London, England)

\begin{tabular}{|c|c|c|c|c|}
\hline Technology & Maturity & Temperature & Source & Products \\
\hline Si CMOS (bulk) & Production & $-50^{\circ} \mathrm{C}$ to $150^{\circ} \mathrm{C}$ & Multiple & $\begin{array}{l}\text { Sensor I/F, Logic, } \\
\text { Memory, Power }\end{array}$ \\
\hline $\begin{array}{l}\text { High-Temp. } \\
\text { Tolerant Si (SOI) }\end{array}$ & Production & $-50^{\circ} \mathrm{C}$ to $300^{\circ} \mathrm{C}$ & Honeywell & $\begin{array}{l}\text { Sensor I/F, Logic, } \\
\text { Memory, Power }\end{array}$ \\
\hline $\begin{array}{l}\text { E/D Gallium } \\
\text { Arsenide (GaAs) }\end{array}$ & Production & $-50^{\circ} \mathrm{C}$ to $150^{\circ} \mathrm{C}$ & Vitesse & Logic, Memory \\
\hline $\begin{array}{l}\text { Complimentary } \\
\text { GaAs }\end{array}$ & Development & $-50^{\circ} \mathrm{C}$ to $350^{\circ} \mathrm{C}$ & Honeywell & Logic, Power \\
\hline $\mathrm{SiC}$ & Development & $-50^{\circ} \mathrm{C}$ to $600^{\circ} \mathrm{C}$ & $\begin{array}{l}\text { CREE, } \\
\text { Siemens, ABB }\end{array}$ & Very Few (Discrete) \\
\hline Diamond & $\begin{array}{l}\text { Early } \\
\text { development }\end{array}$ & $-50^{\circ} \mathrm{C}$ to $1000^{\circ} \mathrm{C}$ & Research labs & None \\
\hline
\end{tabular}


development of reliable integrated circuits to operate for long periods of time at high temperatures. With the fullydepleted SOI MOS technology, Si has very good thermal properties, theoretically reaching temperatures of $400^{\circ} \mathrm{C}$, and low power $\mathrm{Si}$ devices have been widely demonstrated to operate at $300^{\circ} \mathrm{C}$ (Brusius, 1994; Lemnios, 1995; Naefe et al. 1998; Pinardi, 2003; Shahidi et al. 1993). Since by far, most applications operate under $300^{\circ} \mathrm{C}$, Si-based technologies dominate the field now and will for many years to come. Another major selling point for $\mathrm{Si}$ is that the manufacturing technology is already in place for high volume and low cost products.

Alternatively, silicon carbides demonstrated ability to function under extreme high-temperature, high-power, and high-radiation conditions. Therefore, $\mathrm{SiC}$ is expected to enable significant enhancements to a far-ranging variety of applications and systems. Specific applications include high frequency, high power radar systems, jet ignition systems, turbine engine monitoring and control, spacecraft power conditioning, nuclear power instrumentation, in-cylinder engine sensors, and numerous others. However, improvements in crystal growth and device fabrication processes are needed before SiC-based devices and circuits can be scaled-up and reliably incorporated into electronic systems (Eriksson, 2002; Ziegler et al. 2004).

In summary, temperature ranges for high-temperature Electronics can be broken down into 3 ranges as shown in Table 4. Market usage is also shown for relative importance.

Table 4. Recommended technologies for given temperature ranges (HITEN, London, England

$\begin{array}{cccc}\begin{array}{c}\text { Temperature } \\ \text { Range }\end{array} & \begin{array}{c}\text { Percent } \\ \text { of Market }\end{array} & \begin{array}{c}\text { Recommend } \\ \text { for lo-power }\end{array} & \begin{array}{c}\text { Recommend } \\ \text { for hi-power }\end{array} \\ \text { Up to } 200^{\circ} \mathrm{C} & 90.2 \% & \text { SOI } & \text { SOI } \\ 200 \text { to } 300^{\circ} \mathrm{C} & 8.6 \% & \text { SOI } & \text { SiC } \\ \text { Above } 300^{\circ} \mathrm{C} & 1.2 \% & \text { SiC } & \text { SiC }\end{array}$

\subsection{HTEs Devices and Systems}

In the past few years research and development in digital, analog, and power devices for HTEs have been very active. The ultimate goal is to integrate on-chip application-specific integrated circuits (ASICs) as solutions for cost, reliability, space/weight, and power issues. In the following sections, we are going to highlight recent applications.

\subsubsection{Digital Devices}

Table 5 shows, mainly well-documented high-digital devices available in SOI and SiC technology. These devices demonstrated good operations at temperatures up to $300^{\circ} \mathrm{C}$. As can be seen, SOI technology is dominant. Although it is finding wide applications in power systems, it started also in the digital world and a lot of work is being put to produce SiC-based high-temperature digital systems.

\subsubsection{Analog Devices}

High-temperature analog devices such as operational amplifiers (HT1104), analog-to-digital (A/D) converters, analog multiplexers and switches, $5 \mathrm{~V}$ voltage references all operating at $250^{\circ} \mathrm{C}$ and above, and many others are commercially available (not restrictively from Honeywell, IBM, and Cree). A well-documented application of the opamp HT1104 concerns the control of combustion process in engines, as shown in Fig. 3, by either simple flame indicators which have a binary output corresponding to the occurrence of flame or not or more complex light spectrum sensors which have a complete analog output (Sims, 1996).

\subsubsection{Power Devices}

Far-ranging development and applications of power devices have been reported. Recently, for example, in the automotive sector, the impact of $\mathrm{SiC}$ power electronic devices for hybrid electric vehicles, traction drives, DCDC converters, PWM inverters, and IGBTs with field stop

Table 5. Samples of available high-temperature digital devices

\begin{tabular}{|c|c|c|c|}
\hline Part & $\begin{array}{l}\text { Temp. } \\
\text { Range }\end{array}$ & Features & Reference/Source \\
\hline SOI IBM microprocessor & To $300^{\circ} \mathrm{C}$ & $\begin{array}{l}>500 \mathrm{MHz}, 32 \mathrm{~b}, 6.5 \mathrm{M} \\
\text { devices }\end{array}$ & $\begin{array}{l}\text { IBM Microelectronics } \\
\text { Division. }\end{array}$ \\
\hline $\begin{array}{l}\text { SOI microprocessor } \\
\text { HT83C51 }\end{array}$ & To $300^{\circ} \mathrm{C}$ & $\begin{array}{l}\text { 20MHz, 8k ROM, } 256 \\
\text { bytes RAM, 3-16b } \\
\text { timer/counters }\end{array}$ & Honeywell HT83C51 \\
\hline SOI SRAM HT6256 & To $300{ }^{\circ} \mathrm{C}$ & $\begin{array}{l}\text { 200MHz, } 32 \mathrm{kx} 8 \text { static } \\
\text { RAM }\end{array}$ & Honeywell HT6256 \\
\hline SOI CMOS SRAM & To $250^{\circ} \mathrm{C}$ & $64 \mathrm{~kb}$ & (Fallet et al., 1996) \\
\hline $\begin{array}{l}\text { SOI Gate Array HT 2007, } \\
2080,2400\end{array}$ & To $300{ }^{\circ} \mathrm{C}$ & $\begin{array}{l}\text { Sea of } 5 \mathrm{k} \text { to } 200 \mathrm{k} \\
\text { transistor gates }\end{array}$ & $\begin{array}{l}\text { Honeywell HT 2007, 2080, } \\
2400\end{array}$ \\
\hline SiC CMOS ICs & To $300^{\circ} \mathrm{C}$ & $\begin{array}{l}\text { p-well process, } 5 \mathrm{~V} \\
\text { power supply }\end{array}$ & (Ryu et al., 1997, 1998) \\
\hline
\end{tabular}


Flame

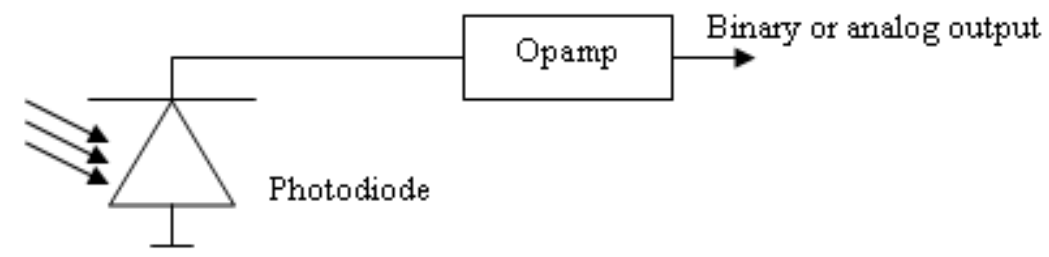

Figure 3. Block diagram of engine combustion control circuit

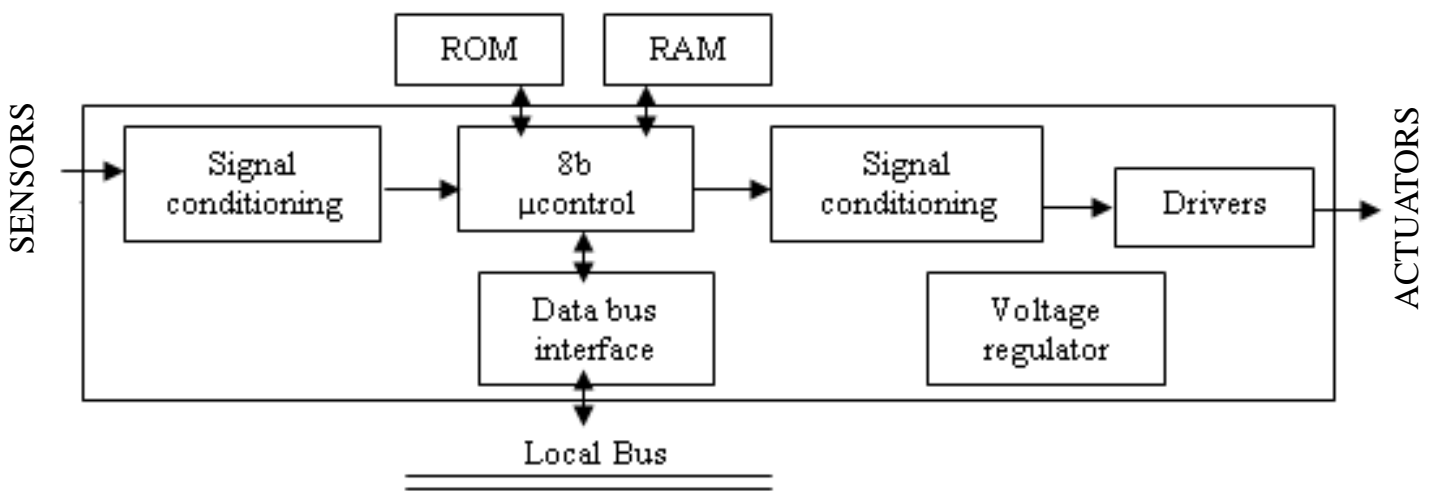

Figure 4. Typical circuit architecture for system monitoring applications

technology was studied (Tolbert et al. 2002 and 2003; Ozpineci et al. 2002; Hasanuzzaman et al. 2004; Spitz et al. 1998; Ishii et al. 2001; Matsumoto et al. 2001; Bauer et al. 2001). Honeywell has reported the availability of power positive and negative linear regulators $(0.5 \mathrm{~A}, \pm 5 \mathrm{~V}$, $\pm 10 \mathrm{~V}, \pm 15 \mathrm{~V}$ ) operating well above $200^{\circ} \mathrm{C}$.

\subsubsection{High-Temperature ASICs}

VLSI technologies today offer the potential for integrating mixed signal circuits as ASICs in high-temperature applications. This solution opens up the possibility of obtaining microelectronics circuits at a lower cost and with better reliability compared to discrete solutions. Furthermore, the scale of the technology leads to reduced power supply voltages, which in turn reduces the field levels, the high-temperature effects and the power consump- tion. As a result, low power supply voltage and high-temperature operation can be used together effectively in the design of high-temperature mixed signal ASICs (Vermesan, 1997). Examples of such implementations are described below.

SSI/LSI Components for hybrid-mounted: Typical system control circuits involve analog and digital signal conditioning and processing, memories and peripherals are implemented (Fallet et al. 1996). Such components are already available for hybrid mounting and operation above $175^{\circ} \mathrm{C}$. Examples of circuits designed for high-temperature operation are shown in Fig. 4.

Control electronics module for future All-Electric Aircraft (AEA): An interesting example is the Actuator Control Electronics (ACE) Module, shown in Fig. 5. It is targeted for completely distributed control in future AEA

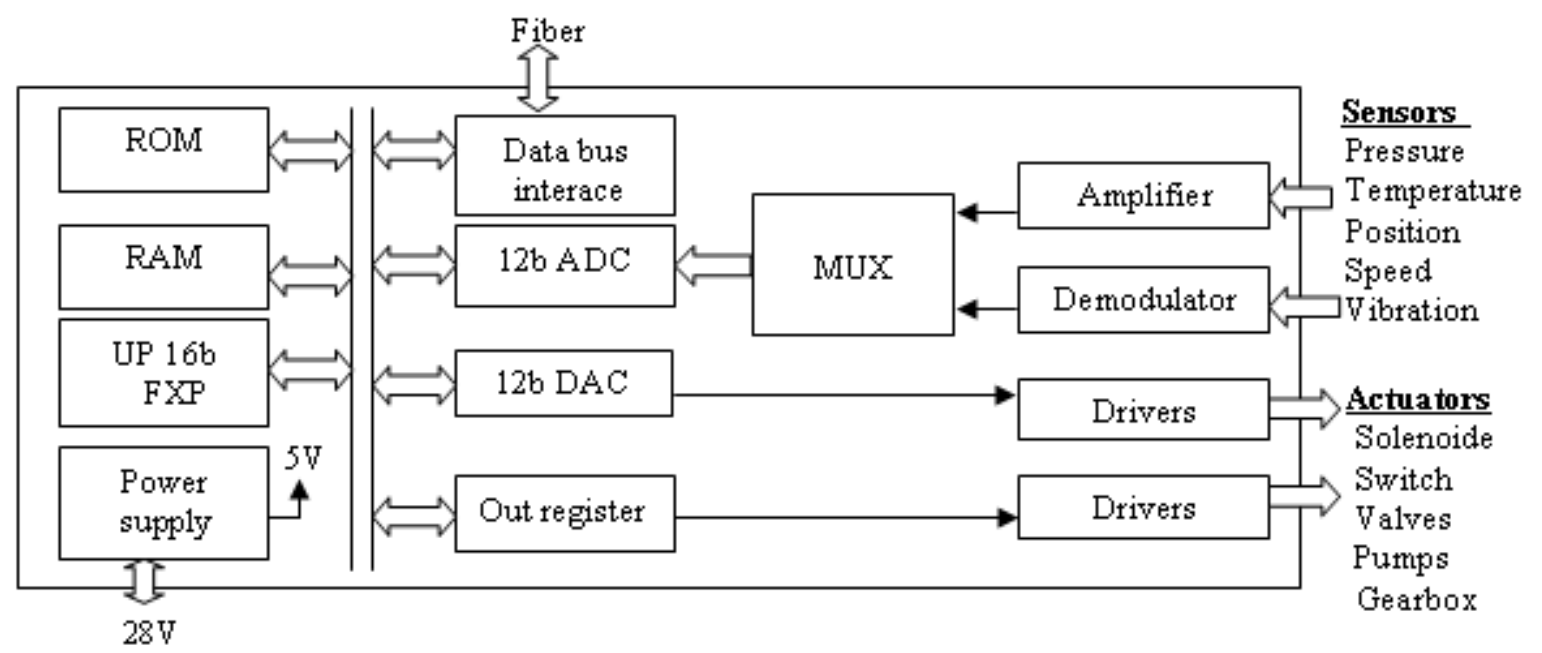

Figure 5. Targeted actuator control electronics module for future AEA applications 


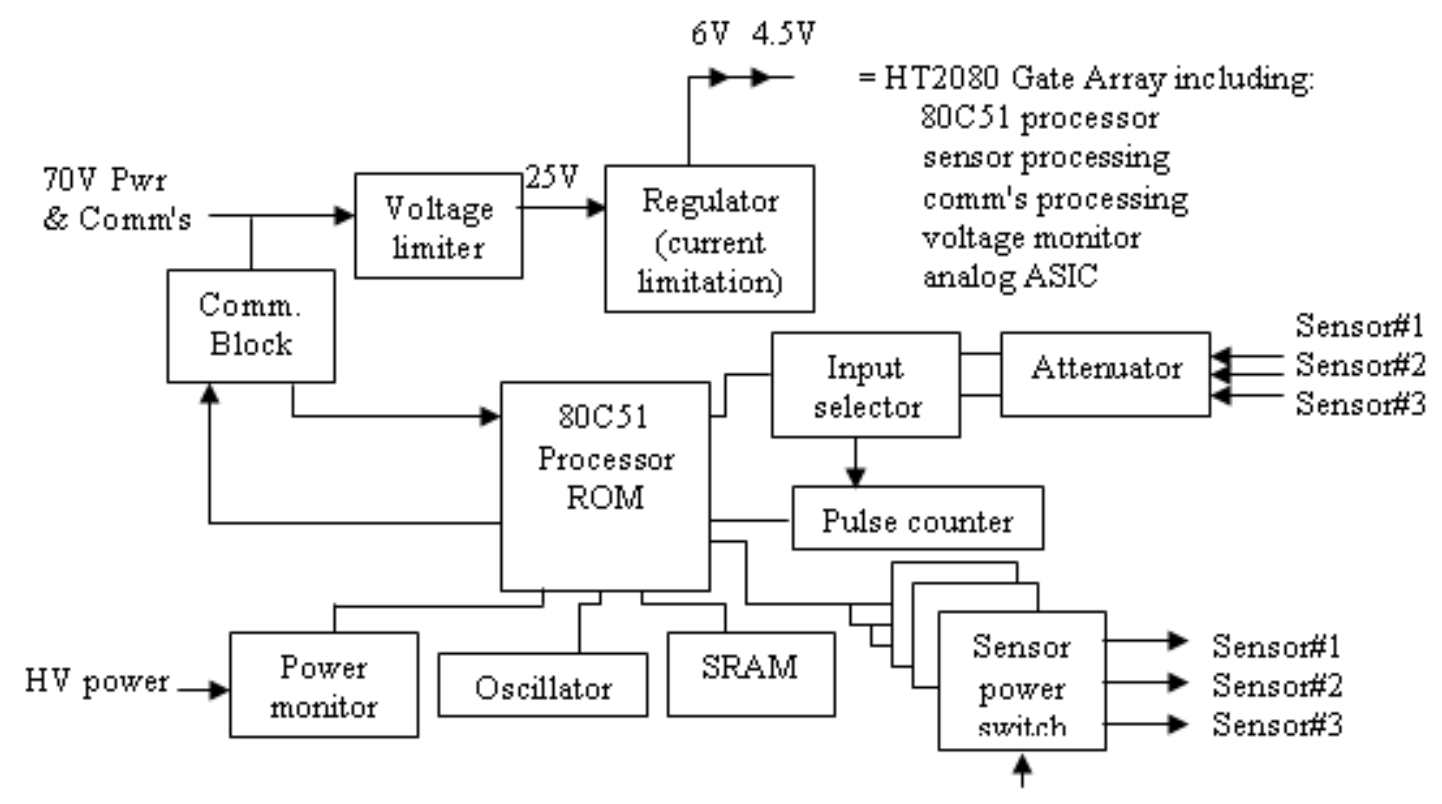

Figure 6. Downhole tool architecture

and operation up to $200^{\circ} \mathrm{C}$ for the wings, $315^{\circ} \mathrm{C}$ for the engines (Bottner et al. 1991). ACE modules will require high-speed data bus interface, large memories, powerful microprocessor, precision analog functions as well as power drivers (Brown et al. 1994). The development of such systems is still years ahead but a few circuits already aim at this direction.

Downhole monitoring: The market for electronics in instrumentation and control systems for downhole applications demands increased performance for gauges both in terms of duration and temperature. Many companies now require instrumentation equipment that can tolerate up to $200^{\circ} \mathrm{C}$ up to two months. There is no doubt as to the future market requirements - even higher temperatures for longer periods.

Figure 6 shows architecture for a wire line permanent gage which utilizes a custom gate array and ASIC to interface pulse width modulated pressure sensors and temperature sensors, and a single bi-directional communication line (Normann et al. 1998).

\subsection{Support Electronics \& Materials Used in Making High-Temperature Circuits}

\subsubsection{Passive \& Discrete Devices}

For passive components, packaging durability at high temperatures is of prime importance. Very often, joining, sealing, and package ruggedness are the main issues affecting the reliability of the components, whereas the basic property materials are very robust. There is a strong desire to use Surface Mount Technology (SMT) components. More passive high-temperature SMT components are now available, making the decision to go to SMT easier (Naefe et al. 1998).

Resistors: Are the largest utilized components in electronic design. Therefore, failure modes, shifts, and ther- mal drifts all can have very detrimental effects on circuits designed for high-temperature operations. Honeywell, Heraeus-Cermalloy, and Huntington Electric have for example, manufactured wire wound, thick-film and thinfilm resistors for power applications. These resistors withstand temperatures above $200^{\circ} \mathrm{C}$ (Naefe et al. 1998; Grzybowski et al. 1998). To stay below their material temperature limits, these resistors should be derated significantly.

Capacitors: The strong temperature dependency of the dielectric constant makes capacitances change significantly with increasing temperature. High-temperature capacitors usually have low capacitance due to mechanical breakage caused by thermal packaging stresses. That is why capacitors will need to be paralleled to get high values. Electrolytic capacitors do not operate above $150^{\circ} \mathrm{C}$ due to dielectric breakdown. Values of several tens of microfarads are typically wet slug Tantalum devices. Solid Tantalum capacitors are available in values of several microfarads. High-temperature ceramic capacitors tend to be very stable for long periods of time exceeding 5000 hours in some tests, however, their values are usually smaller than 0.1 microfarad. Teflon electrostatic capacitors are being developed by Custom Electronics, which have very low TC of capacitance from room to $200^{\circ} \mathrm{C}$, though the parts are usually small valued. Some published temperature test results demonstrate that these capacitors show gradual loss of functionality and initial aging shift in capacitance e.g. Matsuo solid tantalum and NOVACAP ceramic capacitors (Naefe et al. 1998; Grzybowski et al. 1998).

Electromigration: Probably the most significant limiting aspect of an electronic component's lifetime at high temperature is the ability of the metal films to carry currents for extended periods of time. Over years, or even months, with sufficient current density present, metal 
atoms tend to migrate in an uncontrollable dissipation manner (electromigration). Lifetimes can, thus, be improved by reducing current density. Manufacturers of high-temperature-tolerant electronics eliminate this issue by using layout rules that allow at most 1/10 the current density of conventional bulk Si design.

Ohmic contact and packaging: High temperatures cause increased chemical reactivity of metal to Si junctions. Metals with high electrical conductivity present poor interfaces and thus do not form stable ohmic contacts. To overcome this problem, intervening layers of materials (e.g. TiW), called diffusion barriers, that are chemically neutral to the interconnect metal and the semiconductor contact, are being used. A significant amount of study is devoted to researching ohmic contacts in $\mathrm{SiC}$, an issue that has slowed this technology from entering volume production (Cole et al. 2002; Lee et al. 2003; Madsen, 2001; Saxena et al. 1999; Touati and Saji, 1997).

It is also true that packaging and interconnection problems present some of the biggest challenges for electronics at temperatures above $250^{\circ} \mathrm{C}$, often being more of a barrier to successful operation than the intrinsic material issues. When HTEs are exposed to high temperatures for extended periods of time, the materials used for substrates, die attach, wire bonding, and metal interconnects all have to be chosen carefully and should have good hightemperature properties. Some of the important properties for HTEs packaging and interconnections include:

- Materials used should have matching TECs.

- Interfacial materials used should be chemically inert.

- Interconnect metals should not be mixed if possible, to avoid intermetallics.

- Substrates should have high dielectric strength at high temperature.

\subsection{Design Techniques for High-Temperature Applications}

Design for high-temperature applications cannot dispense with circuit techniques to solve problems due to high-temperature operation. By combining techniques such as process technology, physical design, and layout techniques cost effective and reliable high-temperature devices and ASICs can be designed.

Above $200^{\circ} \mathrm{C}$, the SOI and epi-CMOS combined with conservative layout rules (e.g. guarding and interdigitized structures) and techniques such as low power supply voltage, operating the devices into the zero-temperature coefficient (ZTC) biasing point and scaling of transistor aspect ratio offer cost effective solutions for implementing reliable high-temperature systems (Fallet et al. 1994; Shoucair et al. 1984; Vermesan, 1997; Wu and Brown, 1991).

In the Aerospace market today, the SOI technology coupled with the above high-temperature design techniques are being used. There are currently several major projects ongoing which are in various stages of development, testing, and demonstration. The reliability testing of components has been ongoing for several years. Data collection of reliability at the component level has indicated the ability to operate within specification for 5 years or more at $225^{\circ} \mathrm{C}$. These results have included thermal cycling, package mechanical testing as well as accelerated temperature and voltage testing (Hunter, 2004; Lewis, 1998; Naefe, 1998).

In the industrial control and instrumentation arena, high-temperature circuit techniques are used to overcome the inherent drift and non-linearity of sensors, conditioning blocks (e.g. instrumentation amplifiers, A/D converters), and actuators due to temperature effects (Brusius, 1994; Bryzek, 1993). In low-temperature applications inherent drift and non-linearity in the sensor due to temperature effects are generally neglected. High-temperature approaches such as sensor's scaling (Normann and Livesay, 1998), removing of thermal drift of instrumentation amplifiers (Paine Instruments), and overcoming thermal effects when controlling actuators using pulse-width modulation (PWM) signals (Honeywell) were demonstrated.

Consequently, all "screw" it up and let industry and market guide the way.

\section{Market Overview}

The world market for HTE components reached \$148 million in 1995. Industry analysts estimate that this will reach $\$ 1.5$ billion by 2010 as shown in Table 6 . The market is currently quite a bit small; about \$1billion, because of component scarcity, component cost, the lack of semiconductor fabrication facilities capable of producing these devices, and immature packaging and materials technology. It is highly expected that key drivers like well logging equipment, aerospace, and automotive industries, plus several niche applications will boost the HTE market.

Table 6. The world market for high-temperature electronics

\begin{tabular}{|c|c|c|c|}
\hline & 1995 & 2000 & 2010 \\
\hline \multicolumn{4}{|c|}{ Actual Market by Application Sector (\$ million) } \\
\hline Well Logging & 62 & 93 & 313 \\
\hline \multicolumn{4}{|l|}{ Equipment } \\
\hline Aerospace & 6 & 38 & 221 \\
\hline Automotive & 73 & 274 & 848 \\
\hline Other & 7 & 31 & 118 \\
\hline Total & 148 & 436 & 1500 \\
\hline \multicolumn{4}{|c|}{ By Temperature Range, as \% of total } \\
\hline $\mathrm{Up}$ to $200^{\circ} \mathrm{C}$ & 92 & 88 & 80 \\
\hline $200-300^{\circ} \mathrm{C}$ & 8 & 11 & 12 \\
\hline$>300^{\circ} \mathrm{C}$ & 0 & 2 & 8 \\
\hline \multicolumn{4}{|c|}{ By Semiconductor Technology, as \% of total } \\
\hline $\mathrm{Si} / \mathrm{SIO}$ & 88 & 86 & 83 \\
\hline GaAs & 12 & 13 & 9 \\
\hline WBS & 0 & 1 & 8 \\
\hline
\end{tabular}

By temperature range, operation up to $200^{\circ} \mathrm{C}$ satisfies most requirements currently. As the technology matures, 
applications at high temperatures will be enabled and are expected to account for $20 \%$ of the market by 2010 . Sibased technologies dominate applications up to 200$250^{\circ} \mathrm{C}$. GaAs and wide bandgap semiconductors (SiC, diamond and group III nitrides) will play critical roles beyond $250^{\circ} \mathrm{C}$, accounting for $17 \%$ of the market by 2010.

\section{Conclusions}

Status and future prospects of high-temperature electronics have been reviewed. High-temperature electronics are a key enabling technology for many applications in a wide range of industrial sectors. Therefore, they have been recognized as a strategically potential technology. Development of high-temperature electronics is being driven mainly by vertically integrated system organizations in strategic sectors such as oil and gas logging, space, automotive, and communications along with small specialist companies developing new semiconductor technologies. These electronics are based on SOI and wide band-gap semiconductors like silicon carbide, diamond, and oxides by virtue of their superior physical properties compared to those of conventional technologies ( $\mathrm{Si}$, $\mathrm{GaAs}$ ). Modern systems require distributed electronics to achieve adequate performance and accuracy, but conventional components cannot handle high temperatures because of severe derating and thermal wearout. The major market opportunities will arise from incorporating high-temperature electronics in subsystems/systems, as opposed to high-volume component markets. Recently, the technology has witnessed major advancements toward systematic implementations. However, many technical challenges are still pending and need to be surmounted.

\section{Acknowledgments}

The authors wish to thank Sultan Qaboos University (SQU) for providing the facilities and resources.

\section{References}

Bauer O., Auerbach J.G., Porst F., Roth A., Ruething R. and Schilling, H., 2001, "6.5 kV-modules Using IGBTs with Field Stop Technology," IEEE Proceedings of the 13th Int. Symposium on Power Semiconductor Devices and ICs, pp. 121-124, Osaka, Japan.

Bottner, T., 1991, "High-temperature Electronics for Automobile, Aeronautical, Geothermal, Nuclear, and Space," Proceedings of The 1st Int. High-temperature Electronics Conference, pp. 77-82, Albuquerque, NM.

Brown, D. M., 1994, "High-temperature Silicon Carbide Planar IC Technology and First Monolithic SiC Operation Amplifier IC," Proceedings of The 2nd Int. High Temperature Electronics Conference, pp. XI17XI22, Charlotte, NC.
Brusius, P., 1994, "Reliable High-temperature SOI Process," Proceedings of The 2nd Int. High-temperature Electronics Conference, pp. 15-19, Charlotte, NC.

Bryzek, J., 1993, "The Evolution of Smart Sensor and Transducer Design," Sensors, pp. 12-22.

Cole, M.W., Joshi, P. C., Hubbard, C., Demaree, J. D. and Ervin, M., 2002, "Thermal Stability and Performance Reliability of Pt/Ti/WSi/Ni Ohmic Contacts to n-SiC for High-temperature and Pulsed Power Device Applications," J. of Applied Physics, Vol. 91(6), pp. 3864-3868.

Eriksson, J., 2002, Silicon Carbide Microwave Devices,. Publisher: Chalmers University of Technology, Sweden.

Fallet T., 1996, "A High-Temperature Voltage Regulator Chip For Downhole Applications," Proceedings of the 3rd Int. High-temperature Electronics Conference, pp. 3-8, Charlotte, NC.

Fallet, T., Gakkestad, J. and Forre, J., 1994, "Application Specific Integrated Circuits for High Temperature Oil Well Applications," Proceedings of The 2nd Int. High-temperature Electronics Conference, pp. VII9VII14, Charlotte, NC.

Flandre, D. and Colinge, J. P., 1994, "High-temperature Characteristics of CMOS Devices and Circuits on Silicon-on-Insulator (SOI) Substrates," Proceedings of IX SBMICRO 94, pp. 777-786, Rio de Jeneiro.

Grzybowski, R., 1998, "Long Term Behavior of Passive Components for High-temperature Applications-An Update," Proceedings of the High-Temperature Electronic Materials, Devices and Sensors Conference, pp. 172-179, Albuquerque, NM.

Hasanuzzaman, M., Islam, S. K. and Tolbert, L. M, 2004, "Effects of Temperature Variation $\left(300^{\circ}-600^{\circ} \mathrm{K}\right)$ in MOSFET Modeling in 6H Silicon Carbide," Solid State Electronics, Vol. 48(1), pp. 125-132.

Hunter, G. W., Neudeck, P. G., Xu, J., Lucko, D., Trunek, A., Artale, M., Lampard, P., Androjna, D., Makel, D., Ward, B. and Liu, C.C., 2004, "Development of SiCBased Gas Sensors for Aerospace Applications," Materials Research Society Symposium Proceedings, Vol. 815, pp. 287-297, San Francisco, CA, USA.

Ishii, S., Yasuoka, K. and Ibuka, K., 2001, "Pulsed Power Application Assisted by Power Semiconductor Devices," IEEE Proceedings of the 13th Int. Symposium on Power Semiconductor Devices and ICs, pp. 11-14, Osaka, Japan.

Johnson, R. W., Evans, J. L., Jacobsen P., Thompson, J. R. and Christopher, M., 2004, "The Changing Automotive Environment: High-Temperature Electronics," IEEE Transactions on Electronics Packaging Manufacturing, Vol. 27(3), pp. 164-176.

Kodjak, D., 1993, "Emissions, Quantifying the Air Quality Impact of EV Recharging," Green Car J., October Issue, pp. 116-120.

Kodjak, D., 1996, "EVs: Clean Today, Cleaner Tomorrow," Technology Review, August issue, pp. 66-67. 
Lall., P., Pecht, M. and Hakim, E., 1997, Influence of Temperature on Microelectronics and System Reliability: A Physics of Failure Approach. CRC Press, New York.

Lee, B. T., Shin, J. Y., Kim, S. H., Kim, J. H., Han, S. Y. and Lee, J. L., 2003, "Investigation of Ti/Al and TiN/Al Thin Films as the Stable Ohmic Contact for pType 4H-SiC," J. of Electronic Materials, Vol. 32(6), pp. 501-509.

Lemnios, J., 1995, "Manufacturing Technology Challenges for Low Power Electronics," Proceedings of VLSI Technology Symposium, pp. 5-8, Kyoto, Japan.

Lewis, T., 1998, "Military Aircraft Turbine Engine Electronics and Requirements," Proceedings of The 4th Int. High-temperature Electronics Conference, pp. 1-23, Albuquerque, NM.

Ma, Y., Wang, W. L., Liao, K. J. and Kong, C. Y., 2002, "Study on Sensitivity of Nano-Grain ZnO Gas Sensors," J. of Wide Bandgap Materials, Vol. 10, pp. 113-120.

Madsen, L. D., 2001, "Formation of Ohmic Contacts to Ti-SiC and Their Impact on Devices," J. of Electronic Materials, Vol. 30(10), pp. 1353-1361.

Matin, I. H., 1998, "Experts urge All-out Push for NonFossil Energy," Nature, November 19 issue.

Matsumoto, S., Hiraoka S. and Sakai Y., 2001, "A Highefficiency 5-GHz-band SOI Power MOSFET having a Self-Aligned Drain Offset Structure," IEEE Proceedings of the 13th Int. Symposium on Power Semiconductor Devices and ICs, pp. 99-102, Osaka, Japan.

Naefe, J., Johnson, W. and Grzybowski, R., 1998, "Hightemperature Storage and Thermal Shock Studies of Passive Component Attach Materials," Proceedings of The Fourth Int. High-temperature Electronics Conference, pp. 68-78, Albuquerque, NM.

Normann, R. and Livesay, B., 1998, "Geothermal Hightemperature Instrumentation Applications," Proceedings of the 4th Int. High-temperature Electronics Conference, pp. 21-31, Albuquerque, NM.

Ozpineci, B., Tolbert, L. M., Islam, S. K. and Hasanuzzaman, M., 2002, "System Impact of SiC Power Devices," Int. J. of High Speed Electronics and Systems, Vol. 12(2), pp. 439-448.

Patrick, F., McCluskey, Grzybowski, R. and Podlesak, T., 1997, High-temperature Electronicsm. CRC Press, Inc., New York.

Pinardi, K., 2003,"Modelling of High Power SOI Vertical DMOS Transistors and Flip-chip Packages". Doctoral Dissertation, Publisher: Chalmers University of Technology, Sweden.

Prelas, M. A., Ghosh, T. K., Loyalka, S. K. and Tompson, R. V., 2002, "Hydrogen Storage in Diamond Films," J. of Wide Bandgap Materials, Vol. 10, pp. 99-111.

Ryu, S., Kornegay, K. T., Cooper, J. A. and Melloch, M. R., 1997, "6H-SiC CMOS Digital ICs Operating on a
5V Power Supply," IEEE Device Research Conf., pp. 38-39, Fort Collins, CO, USA.

Ryu, S., Kornegay, K.T., Cooper, J. A. and Melloch, M. R., 1998, "Digital CMOS ICs in 6H-SiC Operating on a 5V Power Supply," IEEE Trans. on Electron Devices, Vol. 45(1), pp. 45-53.

Saxena, V., Nong, J. S. and Steckl, A. J., 1999, "HighVoltage Ni- and Pt-SiC Schottky Diodes Utilizing Metal Field Plate Termination," IEEE Transactions on Electron Devices, Vol. 46, No. 3, pp. 456-464.

Shahidi, G. G., 1993, "SOI for a 1-Volt CMOS Technology and Applications to a 512-Kb SRAM with 3.5 ns Access Time," Proceedings of IEDM, pp. 813-816, Washington DC, USA.

Shoucair, F. S., Hwang, W. and Jam, P., 1984, "Electrical Characteristics of Large Scale Integration (LSI) MOSFETs at Very High Temperatures, Part I: Theory," Microelectronics Reliability, Vol. 24(3), pp. 465-485.

Shoucair, F. S., Hwang, W. and Jam, P., 1984, "Electrical Characteristics of Large Scale Integration (LSI) MOSFETs at Very High Temperatures, Part II: Experiment," Microelectronics Reliability, Vol. 24(3), pp. 487-510.

Spitsyn, A. B., Tompson, R.V., Prelas, M. A. and. Ghosh, T. K., 2002, "Charge Carriers Removal from 4HSiC Using Field Enhanced by Optical Activation Diffusion Method," J. of Wide Bandgap Materials, Vol. 10, pp. 89-98.

Spitz, J., Melloch, M. R., Cooper, J. A. and Capano, M. A., 1998, "High-Voltage (2.6 kV) Lateral DMOSFETs in 4H-SiC," IEEE Electron Device Letters, Vol. 19, pp. 100-107.

Sims, P. E., 1996, "High-temperature Electronics for Distributed Control Systems," Proceedings of The 3rd Int. High-temperature Electronics Conference, pp. X9-15, Albuquerque, NM.

Tolbert, L. M., Ozpineci, B., Islam, S. K. and Peng, F. Z., 2003, "Impact of SiC Power Electronic Devices for Hybrid Electric Vehicles," J. of Passenger Cars: Electronic and Electrical Systems, pp. 765-771.

Touati, F. and Saji, M., 1999, "Electrical Properties and Interface Chemistry in Ti/3C-SiC Contact System," Special Issue of the IEEE Transactions on Electron Devices on Silicon Carbide, Vol. 46(3), pp. 186-189.

Vermesan, O., 1997, "ASIC Design for High-Temperature Applications," Proceedings of the 2nd Int. HighTemperature Electronics Conference, Invited Paper, pp. 1-7, Charlotte, NC.

Ziegler, K. J., Lyon., D. M., Holmes, J. D., Erts, D., Polyakov, B., Svensson, K., Olin, H. and Olsson, E., 2004, "Nanomechanical Non-volatile Memory Element," Applied Physics Letters, Vol. 84(20), pp. 4074-4076.

Wu, K. and Brown, R. B., 1991, "High-Temperature Design Rules," Proceedings of the 1st Int. High Temperature Electronics Conference, pp. 267-272, Albuquerque, NM. 